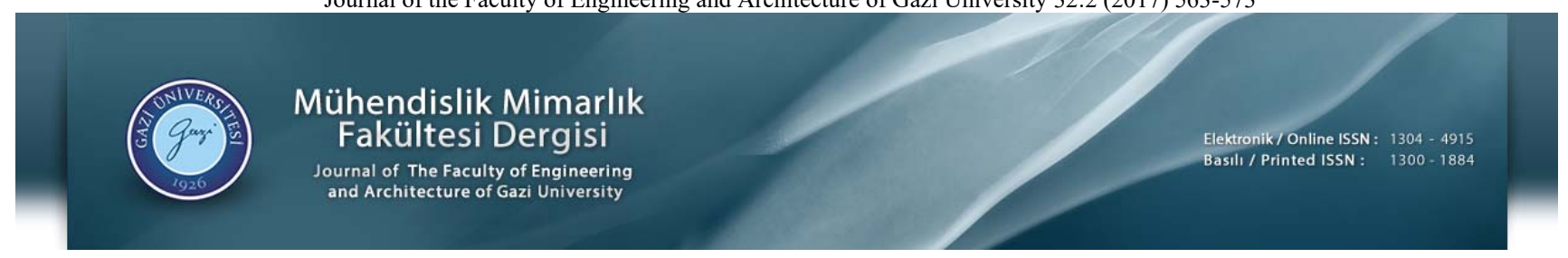

\title{
Elektrot etkileşimi ve uyartım eşiğinin azaltılmasına yönelik sonlu elemanlar yöntemi tabanlı yeni bir retina uyartım stratejisi
}

Mahmut Emin Çelik*, İrfan Karagöz

Gazi Üniversitesi, Mühendislik Fakültesi, Elektrik-Elektronik Mühendisliği Bölümü, Maltepe, Ankara

Ö N E Ç I K A N L A R

- Retina dokusunun farklı elektriksel uyartımlara verdiği tepkinin incelenmesi

- Lokalize uyartım sağlayarak elektrot etkileşimini azaltan uyartım elektrot tasarımı ve yerleşimi

- Doku üzerindeki sıcaklık etkisini azaltan uyartım stratejisi

\begin{tabular}{|c|c|}
\hline & \\
\hline & \multirow{6}{*}{ 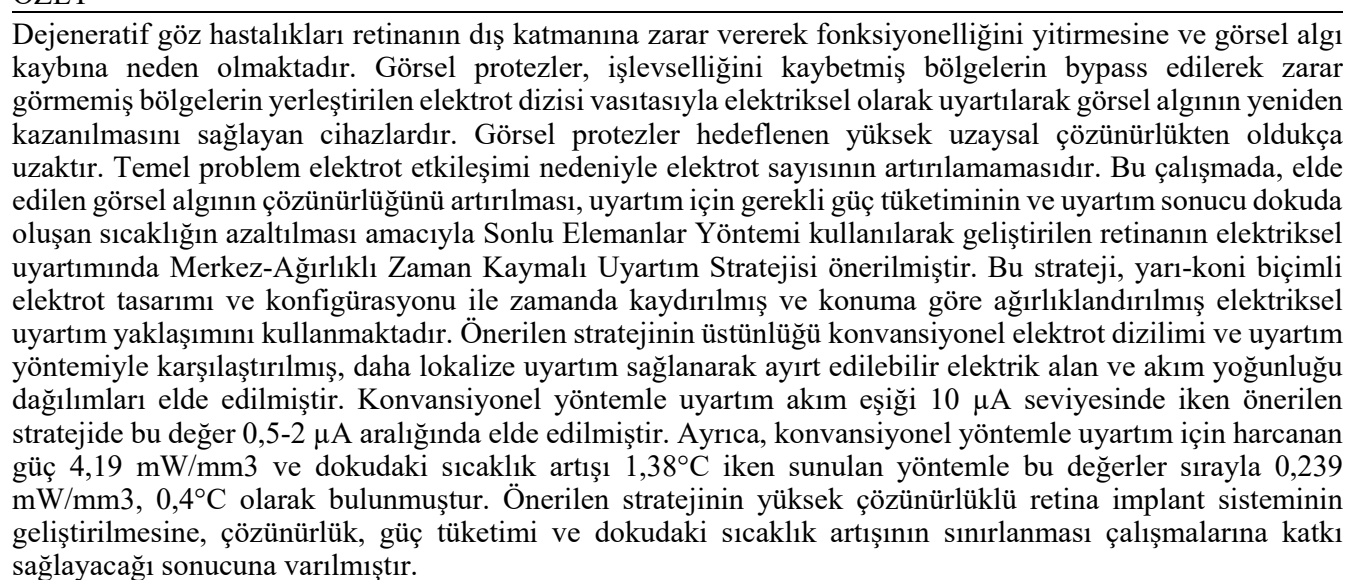 } \\
\hline $\mathrm{Kab}$ & \\
\hline DOI: & \\
\hline 10.17341/gazimmfd.322183 & \\
\hline Anahtar Kelimeler: & \\
\hline & \\
\hline
\end{tabular}

\section{A novel finite element method based retinal stimulation strategy to decrease stimulation threshold and electrode crosstalk}

\section{H I G H L I G H T S}

- Investigation of the retinal responses to different electrical stimulation types

- Stimulation electrode design and its placement that reduce electrode interaction by providing localized stimulation

- Stimulation strategy that reduces the temperature rise over the tissue

\section{Article Info}

Received: 06.05.2016

Accepted: 01.09.2016

DOI:

10.17341/gazimmfd. 322183

Keywords:

Computational modeling, electrical stimulation, temperature,

finite element method, epiretinal visual prosthesis

\section{ABSTRACT}

Degenerative eye diseases damage outer layer of the retina and cause to lost the vision. Visual prostheses are the systems which enable to elicit visual perception through electrical stimulation of the regions that remain intact using electrode arrays at these regions bypassing damaged parts. Spatial resolution of the visual prostheses is far away from the desired value. The main problem is that the number of electrodes couldn't be increased because of electrode interaction. In this study, Central-Weighted Time Shifted Stimulation Strategy which is developed using Finite Element Method is presented which aims both to increase spatial resolution and to decrease power dissipation needed for stimulation and temperature rise on the tissue. This strategy uses semi-cone shaped electrode design and configuration, stimulation approach which is time shifted, weighted depending on the position. Results are compared to the results with conventional electrode layout and stimulation. It is seen that proposed strategy provides discriminable electric field and current density distributions. While stimulation current threshold is $10 \mu \mathrm{A}$ for conventional method, it ranges $0.5-2 \mu \mathrm{A}$ for proposed strategy. Furthermore, power dissipation and temperature rise on the tissue are $4.19 \mathrm{~mW} / \mathrm{mm} 3$ and $1.38^{\circ} \mathrm{C}$ respectively for conventional method, they are $0.239 \mathrm{~mW} / \mathrm{mm} 3$ and $0.4^{\circ} \mathrm{C}$ for proposed strategy. It is concluded that proposed strategy makes a significant contribution to the studies on developing high resolution retinal implant systems in terms of resolution, power dissipation and limitation of temperature rise on the tissue.

\footnotetext{
* Sorumlu Yazar/Corresponding author: mahmutemincelik@gazi.edu.tr / Tel: +90 3125823307
} 


\section{GIRISS (INTRODUCTION)}

Görsel algı, retinanın en dış katmanında 1şı̆̆ın elektriksel sinyale dönüştürülmesi ve bu sinyallerin görsel yolun ilerleyen noktalarında çeşitli uzaysal zamansal sinyal işleme süreçlerinden geçirilmesi ile beyindeki görsel kortekste oluşmaktadır. Tavuk Karası (Retinitis Pigmentosa) ve Yaşa Bağl1 Makula Dejenerasyonu (Age Related Macular Degeneration) gibi göz hastalıkları bu görsel süreci kötü yönde etkileyerek total görme kaybına neden olan ciddi hastalıklardandır. Gelişmiş ülkelerdeki 80 yaş ve üzeri kişilerde görülme oran $1 \% 25$ olarak raporlanan bu iki retina hastalığ 1 dünyada 1,5 milyardan fazla kişiyi etkilemiş bunların 40 milyondan fazlası görme algısını kaybetmiş görme algısını kaybedenlerin \%82'sinin 50 yaş ve üzerinde olduğu belirtilmiştir [1, 2]. Bu hastalıkların yavaşlatıcı tedavi yöntemleri olmasına karşın bilinen ve uygulanan herhangi bir tedavisi bulunmamaktadır [3]. Bu hastalıklar retinanın en dış katmanındaki fotoreseptörlere zarar vermekte, 1şı̆̆ elektriksel sinyale dönüştürmekten sorumlu olan fotoreseptörlerin bozulması ile elektriksel sinyallerin görsel yolda ilerlemesi kesintiye uğramakta ve zamanla görsel alg1 tamamen kaybolmaktadır. $\mathrm{Bu}$ hastalıkların ciddi safhalarındaki deneklerle gerçekleştirilen detaylı çalışmalarda fotoreseptörler önemli ölçüde zarar görse de, uzun süredir göremeyen hastalarda bile iç retina katmanlarındaki sinir hücreleri, retinal gangliyon hücrelerinin ve optik yoldaki diğer iletim bölgelerinin büyük ölçüde zarar görmediği, sağlam kaldığı, morfolojik olarak uygun olduğu rapor edilmiştir [4]. Görsel protez sistemleri, görsel yolda zarar görmüş bölgelerin bypass edilerek fonksiyonel olarak uygun bozulmadan kalan bölgelerdeki sinir hücrelerini o bölgeye yerleştirilen bir elektrot dizisi ile elektriksel olarak uyartarak görsel restorasyonun yeniden kazanımını sağlamayı hedefleyen sistemlerdir. Son yıllarda, elektronik, minyatürizasyon, malzeme, mikroelektronik paketleme gibi farklı alanlardaki ilerlemeler retina protezlerinin geliştirilmesini mümkün kılmıştır [5, 6]. Retina protezleri elektriksel uyartımın gerçekleştirileceği mikroelektrot dizisinin implante edileceği hedef retina bölgesine bağlı olarak 3 ana kategoride sınıflandırılabilir. Epiretinal protezlerde elektrot dizisi retinanın üst yüzeyine yerleştirilir. Çıkışlarındaki sinir telleri optik diski oluşturan retina gangliyon hücrelerinin uyartımı hedeflenmektedir. Hayvan deneyleri ile akut ve kronik insan denemelerinden edinilen bulgular açısından en uzun izleme süresine sahiptir. İnsan denekler ile yapılan klinik çalışmalarla nesnelerin tanındığı, çevrelerinin ayırt edilebildiği ve yüksek doğrulukla harflerin okunabildiği rapor edilmiştir [7]. Subretinal protezler implantasyon için retinanın alt kısmındaki retina pigment epitel katmanı ile foto-reseptör katmanı arasındaki bölgeyi kullanmaktadır. Bu yaklaşımda silikon disk üzerindeki foto-diyotları aktive etmek için yansıyan 1şık kullanılır [8, 9]. Akut ve kronik denemeler geniş harflerin okumanın ve nesne takibinin başarıyla gerçekleştirildiğini göstermiştir [9, 10]. Suprakoroidal protezler ise sklera ile koroid arasındaki bölgenin elektriksel olarak uyartımını esas almaktadır. Klinik denemelerde fosfen algısının elde edildiği raporlanmştır [11]. Retina implantları vasitasiyla elde edilen fosfen algısının, görüntünün, çözünürlüğü kullanılan elektrot sayısına bağlıdır. Hedeflenen çözünürlügün çok uzağında olan mevcut durumda karşılaşılan en büyük problem elektrot etkileşimidir. Elektrot etkileşimi, uyartımın dokuda indüklediği elektrik alanların uzaysal süper pozisyonudur. Üst üste binen elektrik alanlar ayırt edilebilir fosfen algısını, tekil uyartım bölge oluşumunu bozarak uzaysal çözünürlüğün artmasını engeller. Uzaysal seçiciliği olan yüksek çözünürlüklü sistemlerin geliştirilmesi ve retina protezlerinin potansiyelinin tam anlamıla kullanılmasında, uyartım nedeniyle retina dokusunda ortaya çıkan alan dağılımlarının belirli bölgelerde kısıtlanarak lokalize uyartım sağlanarak birbirini etkilemesi engellenmelidir.

$\mathrm{Bu}$ çalışmada, görsel protez sistemlerinde çözünürlüğü artırmak için gereken düşük elektrot etkileşimi, uyartım eşiği, sistemin güvenli sınırlarda uzun süre çalışmasını sağlayacak düşük güç tüketimi ve dokuda indüklenecek en düşük sıcaklık için retina dokusunun elektriksel uyartımında yeni bir yaklaşım olarak Merkez-Ağırlıklı Zaman Kaymalı Uyartım Stratejisi sunulmuştur. Problemin tanımında geliştirilen işlemsel model Sonlu Elemanlar Yöntemi kullanılarak çözülmüştür. Sunulan strateji üç temel bileşene sahiptir. Birinci olarak, elektrot etkileşimini en aza indirmek için gereken lokal uyartımın sağlanması adına en uygun elektrot tasarımı yapılmıştır. Elektrot tasarımına yönelik elektrot boyutu, aralığ1, yüksekliği ve dönüş elektrot boyutu ile uyartım akım genliği optimize edilmiştir. İkinci olarak, geniş toprak elektrotuna sahip elektrot dizilerinin aksine retina anatomisine en uygun merkezde dar ama yoğun, kenarlara doğru genişleyen ancak daha az yoğun altıgen elektrot dizilimi kullanılmıştır. Altıgen dizilim retina dokusunun yapısıyla uyumludur, zira çok yoğun sinir hücresine sahip fovea bölgesi retinanın alan olarak yaklaşık $\% 1$ 'ini oluştururken beyindeki görme merkezinin \%50'sinden fazlasını etkiler [12]. Üçüncü ve son olarak, güç tüketimini en aza indirmek, doku üzerinde indüklenen sıcaklığı azaltmak, uyartım eşiğinin düşürülüp elektrot boyutunun azaltılmasına imkan sağlanmasıyla çözünürlüğün artırılmasını sağlamak ve elektrot etkileşimini en aza indirerek hem fosfen distorsiyonunu azaltmak hem de çözünürlüğü artırmak için aynı sıradaki elektrotların uyartımında merkezden kenara doğru uyartım genliği ağırlıklandırılmış, aynı zamanda sıralı ateşleme sağlayacak faz kaydırılmış bifazik uyartım vurularına sahip gelişmiş bir uyartım yöntemi sunulmuştur. Yöntemin etkinliği standart dizilim ve uyartım yöntemi ile karşılaştırılmıştır. Burada elektrot çap1, elektrotlar arası mesafe, uyartım akım genliği gibi uyartım, elektrot şekli ve dizilimi gibi tasarım parametreleri incelenerek önerilen model elektrik alan, akım yoğunluğu, sıcaklık açısından irdelenmiştir. Diğer yandan, tavşan retinası kullanılarak gerçekleştirilen in vitro deneysel çalışmalar ile bifazik uyartım vurularının altıgen dizilime sahip bir elektrot dizisindeki aksiyon potansiyeli tespitinde eşik akımı ve elektrot çapının etkisi incelenmiştir. 


\section{MATERYAL VE METOD (MATERIALS AND METHOD)}

\subsection{Işlemsel Retina Modeli ve Tanımlayan Eşitlikler \\ (Computational Retina Modeling and Governing Equations)}

Sonlu elemanlar yöntemi ile modelleme diferansiyel denklemler ile ifade edilen ve daha önceden tanımlanmış sınır koşullarına sahip bir problemi çözen nümerik bir yöntemdir. Problem domainleri, düğümler içeren sınırlı büyüklükteki elementlere ayrılır. Diferansiyel denklemler, sınır koşullarını kullanarak düğüm düğüm hesaplanarak çözülür. Retinanın elektriksel uyartımını modelleme problemine retina dokusunun modellenmesi ile başlanmıştır. Uyartım modeli retina dokusu ve üzerine yerleştirilen elektrotlardan oluşan gerçeğine uygun 3 boyutlu sunulmuştur. Retina ve elektrotlardan oluşan iki domain belirlenmiştir. Retina dokusunun homojen ve isotropik olduğu varsayılmıştır. Retina dokusu ve elektrotlar ile ilgili parametreler öncü deneysel çalışmalarda belirlenmiştir [13, 14]. $\mathrm{Bu}$ çalışmada diferansiyel denklemlerin çözümünde kullanılan parametreler Tablo 1'de sunulmuştur $[15,16]$.

Tablo 1. İşlemsel modelde kullanılan parametreler (Parameters used for computational model)

\begin{tabular}{lll}
\hline Parametre & Değer & Birim \\
\hline Elektriksel & 0,0226 & $\mathrm{~S} / \mathrm{m}$ \\
İletkenlik & 1 & 1 \\
Bağ1l Yalıtkanlık & 1 & $\mathrm{~W} /(\mathrm{m} . \mathrm{K})$ \\
Termal İletkenlik & 0,528 & $\mathrm{Kg} / \mathrm{m}^{3}$ \\
Yoğunluk & 1040 & $\mathrm{~J} /(\mathrm{kg} . \mathrm{K})$ \\
Sicaklık & 3650 & $\mu \mathrm{m}$ \\
Kapasitesi & 300 & $\mu \mathrm{m}$ \\
Kalınlık & 4000 & $\mu \mathrm{s}$ \\
$\begin{array}{l}\text { Genişlik } \\
\text { Vuru Periyotu }\end{array}$ & 200 & ${ }^{\circ} \mathrm{C}$ \\
Sicaklık & 36 & $\mu \mathrm{m}$ \\
$\begin{array}{l}\text { Elektrot Çapı } \\
\text { (Sunulan, }\end{array}$ & $40-125,400$ & \\
$\begin{array}{l}\text { Standart) } \\
\text { Elektrot Arallı̆1 } \\
\text { (Sunulan, }\end{array}$ & & $\mu \mathrm{m}$ \\
Standart) & $90-190,300$ & \\
\hline
\end{tabular}

Elektrot tasarımında düzlemsel ve büyük boyutlu toprak elektrotu kullanımının elektrot etkileşimine neden olarak çözünürlügün artırılmasını engelleyen bu dezavantajını ortadan kaldırmak ve uyartım elektrotu ile toprak arasında oluşturulan hedef uyartım bölgesini lokalize etmek amacıyla yar1-koni biçimli düzlemsel olmayan dokuya nüfuz eden elektrot yapısı önerilmiştir, Şekil 1 Yarı-koni biçimli yapının taban yüzeyi uyartım alanı, Şekil 1 sağ üst gösterimin merkezindeki dairesel yüzey, olarak kullanılırken üst silindirik yüzey, Şekil 1 sol üst gösterimin mavi ile taranmış olan üst silindirik çember bölge, toprak elektrotu olarak kullanılmıştır. Elektrot etkileşimini azaltmak, uyartım eşiğini düşürerek harcanan güç ve sıcaklık gibi parametreler açısından daha düşük sınırlarda uyartımı mümkün kılıp çözünürlüğü artırmak için kullanılan uyartım stratejisinde uyartım vuru genlikleri elektrotların yerine göre ağırlıklandırılmış ve bu uyartım vuruları arasına zaman farkı uygulanarak elektrotların sırayla ateşlenmesi sağlanmıştır. 4 elektrotun olduğu bir hat boyunca her bir elektrota farklı uyartım sinyalleri uygulanmış olup bunların her biri $200 \mu \mathrm{s}$ periyoda sahiptir. Pozitif ve negatif alternansların ardından uyartımsız bir zaman aralığı bırakılmıştır. Tavşan retinası ile gerçekleştirilen in vitro deneylerde hangi uyartım tipinin daha uygun olduğu ve hangi elektrot boyutunun daha çok aksiyon potansiyeli algılayacağı irdelenmiştir. Problemin çözüm modeli 2 boyutlu eksen simetrik olarak yapılmıştır. Modelin boyutları $4 \mathrm{~mm}$ x $4 \mathrm{~mm}$ x 0,3 mm'dir. 3-boyutlu temsili gösterimdeki elektrot yerleşimi, elektrot boyut ve aralık değerleri kullanılarak belirlenmiş bir hat üzerinde çözüm gerçekleştirilmiştir. Modelin tanımını yapan ve çözümünü içeren diferansiyel denklemler aşağıda sunulmuştur. Elektriksel uyartım tarafından üretilen elektrik ve manyetik alan davranışı Maxwell denklemleri ve ilişik eşitlikler ile ifade edilir $[17,18]$.

$$
\begin{aligned}
& \nabla \cdot D=\rho \\
& \nabla \cdot B=0 \\
& \nabla \times E=\frac{\partial B}{\partial t} \\
& \nabla \times H=J_{t o t}
\end{aligned}
$$

Eş. 1-4'te $\mathrm{D}(D=\varepsilon E)$ elektrik akı yoğunluğu, $\varepsilon$ ortamın dielektrik sabiti, E elektrik alan şiddeti, B manyetik ak1 yoğunluğu $(B=\mu H), \mu$ manyetik geçirgenlik, $H$ manyetik alan, $\rho$ yük yoğunluğu ve $J_{\text {tot }}$ toplam akım yoğunluğudur. Eğer hücre dışı elektriksel uyartım uygulanırsa, $\mathrm{J}_{\text {tot, }}$, uyartım akımı $\mathrm{J}_{\mathrm{p}}$ indüklenen iletim akımı $\sigma \mathrm{E}$, ki burada $\sigma$ elektriksel iletkenliktir, ve indüklenen yer değiştirme akımının $\partial D$ / $\partial t$ toplamına eşit olan Eş. 5 ile ifade edilir [19].

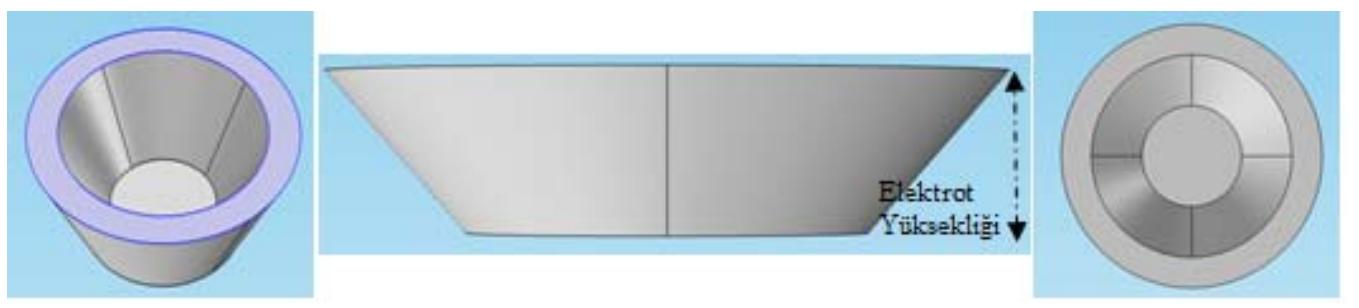

Şekil 1. Tasarlanan elektrot geometrisinin şematik gösterimi. Üç boyutlu görünüm (sol), yandan görünüm (orta), yukarıdan görünüm (sağ)

(Schematic presentation of designed electrode geometry. 3-d view (top left), aerial viewpoint (top right), side view (bottom)) 
$J_{t o t}=J_{p}+\sigma E+\partial D / \partial t$

Elektrik alan E skaler $\mathrm{V}$ elektrik potansiyeli ve A vektör potansiyeline bağlıdır ve Eş. 6 ile hesaplanır:

$E=-\nabla V-\frac{\partial A}{\partial t}$

Lorentz ölçüsü vektör ve skaler potansiyelleri A ve V'nin tanımlanması için kullanılır:

$\nabla \cdot A=-\mu \varepsilon \frac{\partial V}{\partial t}$

Çözümlerde kolaylık sağlamak için Eş. 1-7'deki zamana bağımlı değişkenlik ihmal edilebilir. Biyo-elektrik kaynaklar için geçerli olduğu gösterilen yarı-statik yaklaşım düşük frekanslarda yayilım, kapasitif ve endüktif etkilerin ihmal edilebilmesini sağlar [20]. Eş. 8-11 yardımıyla, elektrik alan yarı-statik yaklaşımlarla Maxwell denklemlerini çözerek hesaplanmaktadır [21, 22].

$$
\begin{aligned}
& \nabla \cdot J=0 \\
& \nabla \cdot E=\frac{\rho}{\varepsilon} \\
& \mathrm{J}=\sigma \mathrm{E} \\
& \mathrm{E}=-\nabla \mathrm{V}
\end{aligned}
$$

Yarı-statik yaklaşım altında $\mathrm{V}$ elektriksel potansiyeli Eş. 4'ün diverjansı alınarak Eş. 5-6'da yerine yazılması ile Eş. 12 bulunur, ki bu Poisson eşitliğidir.

$$
\nabla^{2} \mathrm{~V}=\frac{\rho}{\varepsilon}
$$

Poisson eşitliği izotropik homojen olmayan bir ortamda en az bir kaynak olduğu anlamına gelir. Eğer ortamda kaynak yoksa ve doku homojen ve elektriksel iletkenliğe sahipse Poisson denklemi Eş. 13'teki Laplace denklemi halini alır:

$\nabla^{2} \mathrm{~V}=0$

Dokuların elektriksel olarak uyartımında Joule ve metabolik tepkiler dolayısıyla sicaklık artar [23, 24]. Joule etkisi elektrik alan varlığında oluşur. Modelin çözümünde sıcaklık etkisinin hesaplanmasında Pennes biyo-sıcaklık eşitliği esas alınmıştır:

$$
\nabla \cdot(-\mathrm{k} \nabla \mathrm{T})=\rho_{b} C_{b} \omega_{b}\left(T_{b}-\mathrm{T}\right)+Q_{\text {met }} Q_{e x t}
$$

Eş. 14'te $\mathrm{k}, \rho_{\mathrm{b}}, \mathrm{C}_{\mathrm{b}}, \omega_{\mathrm{b}}, \mathrm{Q}_{\mathrm{met}}$, $\mathrm{Q}_{\text {ext }}$ srrasıly termal iletkenlik $(\mathrm{W} / \mathrm{mK})$, yoğunluk $\left(\mathrm{kg} / \mathrm{m}^{3}\right)$, bir birim sıcaklık değişimi üretebilecek enerji miktarı olan özgül sıcaklık kapasitesi (J/kg.K), bir birim doku boyunca her saniye akan kan hacmi $(1 / \mathrm{s})$, metabolizmanın sicaklık kaynağı ve dış sıcaklık kaynağını $\left(\mathrm{W} / \mathrm{m}^{3}\right)$ ifade eder. Hacim denklemlerinin belirlenmesinin ardından modelin sınır koşullarının belirlenmesi gerekmektedir. Bunlar lokal kısıtlar olarak ortaya çıkar. Eş. 15, model dışında herhangi bir akımın akmadığı, özellikle yalıtım elemanları, yalıtkan sınırlar aşağıdaki homojen Neumann sınır koşulları ile ifade edilmektedir:

$\sigma \nabla \mathrm{V} \cdot \mathrm{n}=0$

burada soldaki ilk ifade lokal yüzey akım yoğunluğu, $n$ ise sınıra dik normal birim vektördür. Benzer şekilde Eş. 16 dış sınırların izole edildiği sınırdan herhangi bir akım olmadığı belirtilmektedir.

n. $J=0$

Akım yoğunluğunun korunumu sınır koşulu sınırdaki her noktada sağlanmalıdır. Bir ortamın sınırındaki akım yoğunluğunun normal bileşeni diğer ortamın dışına akan akım yoğunluğunun normal bileşeni ile eşit olmalıdır (Eş. 17).

$n_{2}\left(J_{1}-J_{2}\right)=0$

Uyartım ve toprak elektrotları için en sık kullanılan Dirichlet sınır koşuluna göre uyartım elektrotuna uygulanacak uyartım sinyali verilirken, toprak elektrotu 0 olarak belirlenmiştir. Metal elektrottaki sinyal dokuya direk olarak iletilir. Toprak olarak seçilen noktalar sifir elektriksel potansiyel göstermektedir.

\subsection{In Vitro Deneyler İçin Retinanın Hazırlanması \\ (Retinal Preparation for In Vitro Experiments)}

Hayvanların bakım ve kullanımında Gülhane Askeri Tıp akademisi (GATA) Hayvan Deneyleri Etik Kurallarına uyulmuştur. Karanlık adaptasyonu yapılmış $2-3 \quad \mathrm{~kg}$ ağırlığındaki dişi Yeni Zelanda tipi tavşanlar kullanılmıştır. Denek ilk olarak kas arasina ketamine $(40 \mathrm{mg} / \mathrm{kg})$ and xylazine $(10 \mathrm{mg} / \mathrm{kg})$ karışımı uygulanarak sakinleştirilmiştir. Ardından, yüksek doz sodyum pentobarbital uygulaması ile sakrifiye edilmiştir. Göz küresinin enüklasyonunu müteakip gözün ön bölümü ve vitröz atılmıştır. Yaklaşık 4 mm'lik bölütlere ayrılan göz küresi Ames (Sigma Chemical Co.) solüsyonuna alınmıştır. Sakrifiye işleminden solüsyona alınma aşamasına kadar geçen süre 4-9 dakika arasındadır. Ames solüsyonu sodyum bikarbonat ile tamponlanmış ve 95\% oksijen ve 5\% karbondioksitten oluşan gaz karışımı ile havalandırılmıştır. Daha sonra, sklera, retina pigment epiteli ve iç zarlar kaldırılarak retina dokusu izole edilmiştir. Bir retina bölütü ile az miktar solüsyon mikro-elektrot dizisi çemberine retina gangliyon hücre tabakası elektrotlara gelecek şekilde yerleştirilmiştir. Retina dokusunun elektrotlara daha iyi yapışması için solüsyon geri çekilmiştir. Retinanın daha uzun süre canlı kalması ve sinyalde bozulma olmadan daha iyi kayıt yapabilmek için ortam sıcakl $\operatorname{lğ}_{1} 37^{\circ} \mathrm{C}$ olarak ayarlanmış ve besleyici solüsyon elektrot çemberine perfüze edilmiştir. $\mathrm{Bu}$ aşamalar loş kırmızı 1 şk altında gerçekleştirilmiştir. Standart çözelti (çözünen mM: 100 $\mathrm{NaCl}, 30 \mathrm{NaHCO}_{3}, 50$ glikoz, $6 \mathrm{KCl}, 2 \mathrm{MgSO}_{4}, 1 \mathrm{CaCl}_{2}, 1$ $\left.\mathrm{NaHPO}_{4}\right) 37 \pm 1^{\circ} \mathrm{C}$ 'de $7.5 \pm 0.2 \mathrm{pH}$ değerine sahip $95 \% \mathrm{O}_{2}$, $5 \% \mathrm{CO}_{2}$ ile havalandırılmıştır. 


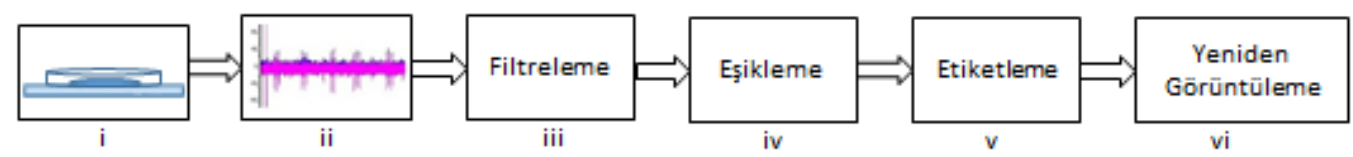

Şekil 2. Aksiyon potansiyeli izolasyonunda izlenen sinyal işleme adımları (Signal processing steps for spike isolation)

\subsection{In Vitro Elektriksel Uyartım ve Aksiyon Potansiyeli \\ Analizi (In Vitro Electrical Stimulation and Spike Analysis)}

Elektriksel uyartım ve kayıt işlemi için kullanılan sistem bir takım temel bileşenlere sahiptir. Bunlar mikroelektrot dizisi (60HexaMEA-Ti, Multi Channel Systems GmbH, Germany), yükselteç (MEA1060-Amplifier, Multi Channel Systems GmbH, Germany), veri toplama ve yazılım, uyartım jeneratörü (STG4002, Multi Channel Systems GmbH, Germany), perfüzyon sistemi (PPS2, Multi Channel Systems $\mathrm{GmbH}$, Germany) ve sicaklık kontrolörüdür. In vitro deneylerde kullanılan hekzagonal dizilime sahip mikroelektrot dizisi 60 elektrota sahiptir. Elektrot boyutları $10,20,30 \mu \mathrm{m}$ arasında değişirken elektrotlar arası mesafeler $30,60,90 \mu \mathrm{m}$ 'dir. 60 elektrottan gelen bilgiler yükseltece iletilir. Yükselteç 1-5000 Hz bant genişliğine sahiptir ve kazancı 1000'dir. Çalışmalar esnasında yükselteç Faraday kafesi benzeri bir düzenekle izole edilmiştir. Örnekleme frekansı $25 \mathrm{kHz}$ 'dir. 10-120 $\mu \mathrm{A}$ arasında değişen genlik ve 100-200 $\mu$ s pals genişliklerine sahip monofazik, bifazik uyartım trenleri hazırlanmış olup uyartım jeneratörü vasitasıyla retina dokusuna uygulanmak üzere daha önceden seçilmiş elektrotlara iletilmiştir.

Elektriksel uyartımı müteakip elektriksel uyartıma bağlı nöral aktivitenin oluşumu gözlemlenmiştir. Ham nöral dalga formları MATLAB ortamına aktarılmış ve geliştirilen algoritma ile analiz edilerek yorumlanmak üzere sayısal sonuçlar elde edilmiştir. Geliştirilen algoritma ile aksiyon potansiyeli izolasyonuna dair işlem adımları Şekil 2'de sunulmuştur.

$\mathrm{Bu}$ kapsamında gerçekleştirilen çalışmalar, (i) in vitro deneyler ile tavşan retinasındaki elektriksel aktivitenin algılanarak kaydedilmesi ile başlamış, ardından (ii) kaydedilen sinyaller MATLAB ortamına alınmış, (iii) düşük frekans lokal alan potansiyelleri ile yüksek frekans termal ve elektriksel gürültüyü elemine etmek için filtreleme adımı gerçekleştirilmiş, (iv) literatür ile uyumlu olarak sinyal ortalamasının yaklaşık 2-4 katı arasında bir genlik, $40 \mu \mathrm{V}$, seçilerek sinyal eşiklenmiş, (v) eşiklenmiş sinyal üzerindeki yanlış alarmları azaltmak üzere uygun yazılımsal modifikasyonları içeren etiketleme aşaması ile aksiyon potansiyelleri izole edilmiş ve (vi) ileri işleme süreci için yeniden görüntülenmiştir. Kayıtta arka plana gömülü rastgele aktivitenin yanıltıcı etkisini bertaraf etmek için elektriksel aktiviteye bağlı aksiyon potansiyeli oluşumunun gözlemlenmeye başlamasından itibaren 10 saniyelik örnek bölümleri kaydedilmiştir. $\mathrm{Bu}$ örneklerdeki izole edilmiş ortalama aksiyon potansiyeli sayısı hesaplanarak hedeflenen aralıktaki sayıdan çıkarılmıştır.

\section{SONUÇLAR VE TARTIŞMALAR (RESULTS AND DISCUSSIONS)}

Klinik denemelerde elde edilen fosfen algısı yuvarlak, oval olarak tanımlandığı gibi düzensiz şekillerde de raporlanmıştır [25, 26]. Düzenli fosfen oluşumu için lokalize uyartım ile yalnızca uyartım yapılan elektrot etrafinda alan oluşturmak gerekir [27]. Bu sayede, hedeflenen noktanın çok uzağında olan, 16 piksel, uzaysal çözünürlügüün de artırılması mümkün olur. Elektriksel sinir uyartımın işlemsel modellemesi farklı uyartım ve tasarım parametrelerinin daha hızlı ve verimli olarak incelenebilmesi sağlar. Sonlu Elemanlar Yöntemi elektrotların uyartımı ile dokuda görülen elektrik alan hesabında kullanılan yöntemlerden birisidir [28, 29]. Görsel protezlerin geliştirilmesinde potansiyel dağ $11 \mathrm{~m}$ hesabında, düzlemsel elektrotların üç boyutlu elektrik alan dağılımında ve farklı konfigürasyonların incelenmesinde daha önce kullanılmıştır $[30,31]$. Greenberg ve arkadaşları farklı nöron modelleri kullanarak en düşük uyartım eşik değerini tespit etmek için çalışırken retina gangliyon hücrelerinin yapısal özellikleri göz önünde bulundurulmuştur [32, 33]. Uyartım elektrotu olarak noktasal kaynaklar, tekil düzlemsel disk elektrotlar, düzlemsel olmayan elektrotlar ve son zamanlarda çokluelektrot yapısı kullanılmıştır [34]. Elektrot yüzey alanının artırılmasının uyartım verimini artıracağı ve daha düşük akımlarla uyartım yapılabileceği rapor edilmiştir [35]. Diğger bir grup uyartım eşiğini azaltmak için geometrik etkenleri incelenmiş, elektrot çapının azaltılması gerekliliği vurgulayarak bunun hem uyartım eşiğini azaltacağı hem de çözünürlüğü artıracağını ifade etmiştir [36]. Görsel bilginin daha iyi haritalanması ve fonksiyonel performansın artırılması için farklı elektrot konfigürasyonları, uyartım yöntemleri denenerek sanal kanal yöntemi önerilmiştir [37]. Retina dokusu üzerine yerleştirilen uyartım elektrotları ile retina dokusunda ortaya çıkan alanlar incelenmiştir. Ardından, uyartım sonucu ortaya çıkan güç ve bundan dolayı retina dokusunda indüklenen sıcaklık artışı ortaya konmuştur. Çözümler uyartım vuruları boyunca $1 \mu \mathrm{s}$ çözünürlükle gerçekleştirilmiştir. Doku üzerinde ortaya çıkan 1000-3000 V/m aralığındaki elektrik alanın sinir hücrelerinin uyartımında etkin aralık olduğu literatürde raporlanmıştır [38]. Bu göz önünde bulundurularak bu aralıkta elektrik alan üreten uyartım kısıtları optimize edilerek uyartım akımı belirlenmiştir. Problemlerin çözümünde 2 boyutlu eksen simetrik yapı kullanılmıştır.

\subsection{Konvansiyonel Elektrot Dizisi ve Uyartım Yöntemi (Conventional Electrode Array and Stimulation Method)}

Standart elektrot dizisinin sıradan bir uyartım yaklaşımı ile uyartımı sonucu ortaya çıkan alanlar incelenmiştir. Üzerinde 
en çok çalışılan insan denekler üzerinde uzun süren kronik testleri devam eden 4'e 4 dizilimli 16 elektrotlu sistemler en sık karşılaşılan dizilim olduğundan tercih edilmiştir. Uyartım sinyalleri 100'er $\mu$ s pozitif ve negatif alternanslara sahip 200 $\mu$ s periyotlu bifazik dalga formlarıdır. Uyartım genliği $10 \mu \mathrm{A}$ uygulanarak etkin elektrik alan aralığı elde edilmiştir. Elektrot bölgesinin yüzeyinden retina dokusunun içerisine doğru $h$ aralığında bir kesim hattı tanımlanarak doku boyunca elektrik alan ve akım yoğunluğu incelenmiştir. Uyartım elektrotları ile toprak elektrotu arasında aktif bir uyartım alanı oluştuğu görülmektedir. $\mathrm{Bu}$ alan boyunca toprak elektrotuna yaklaşıldıkça elektrik alan normu ile akım yoğunluğunun artan bir eğilim gösterdiği gözlemlenmiştir. Şekil 3-b'de retina dokusuna 10, 30, $50 \mu \mathrm{m}$ nüfuz edildiğinde görülen elektrik alan normu 200-4100 V/m aralığındadır. Şekil 3-c'de elektrot yüzeyindeki akım yoğunluğu normu en yüksek $280 \mathrm{~A} / \mathrm{m}^{2}$ 'dir. Geniş bir toprak elektrotunun kullanıldığı tasarımlarda oluşacak elektrik alan uyartımtoprak elektrotu arasında olacağından elektrot etkileşimi ile karşılaşılacaktır. Hedeflenen elektrik alan dağılımı için 10 $\mu \mathrm{A}$ gerekmektedir. Şekil 3-a'da her elektrottan uygulanan akım toprak vasitasıyla tamamlandiğından elektrot etkileşimi söz konusudur. Şekil 3-b'de elektrotların toprak elektrotuna yakın sınırlarında elektrik alan en yüksek değerlerde sahip iken elektrot yüzeyinden dokunun derinliklerine ilerlendiğinde daha yumuşak geçişler gözlemlenmiştir. Şekil 3-c'de akım yoğunluğunun en yüksek değerinin dönüş elektrotunun köşesi olduğu görülmektedir. Tek bir dönüş elektrotunun olduğu elektrot dizilerinde, toprak elektrotuna uzak elektrottan yakın olanına doğru yaklaşırken oluşan elektrik alanın arttığı görülmüştür.

\subsection{Merkez-A $\breve{g}$ ırlıklı Zaman Kaymalı Uyartım Stratejisi (Central-Weighted Time Shifted Stimulation Strategy)}

Yarı-koni biçimli elektrot ve elektrot dizisi tasarımı ile ağırlıklandırılmış zaman kaymalı uyartım yöntemi kullanılarak gerçekleştirilen uyartım sonucu retina dokusundaki dağılımlar incelenmiştir. Aynı hattaki dört elektrota farklı uyartım sinyalleri uygulanmıştır. Genlik
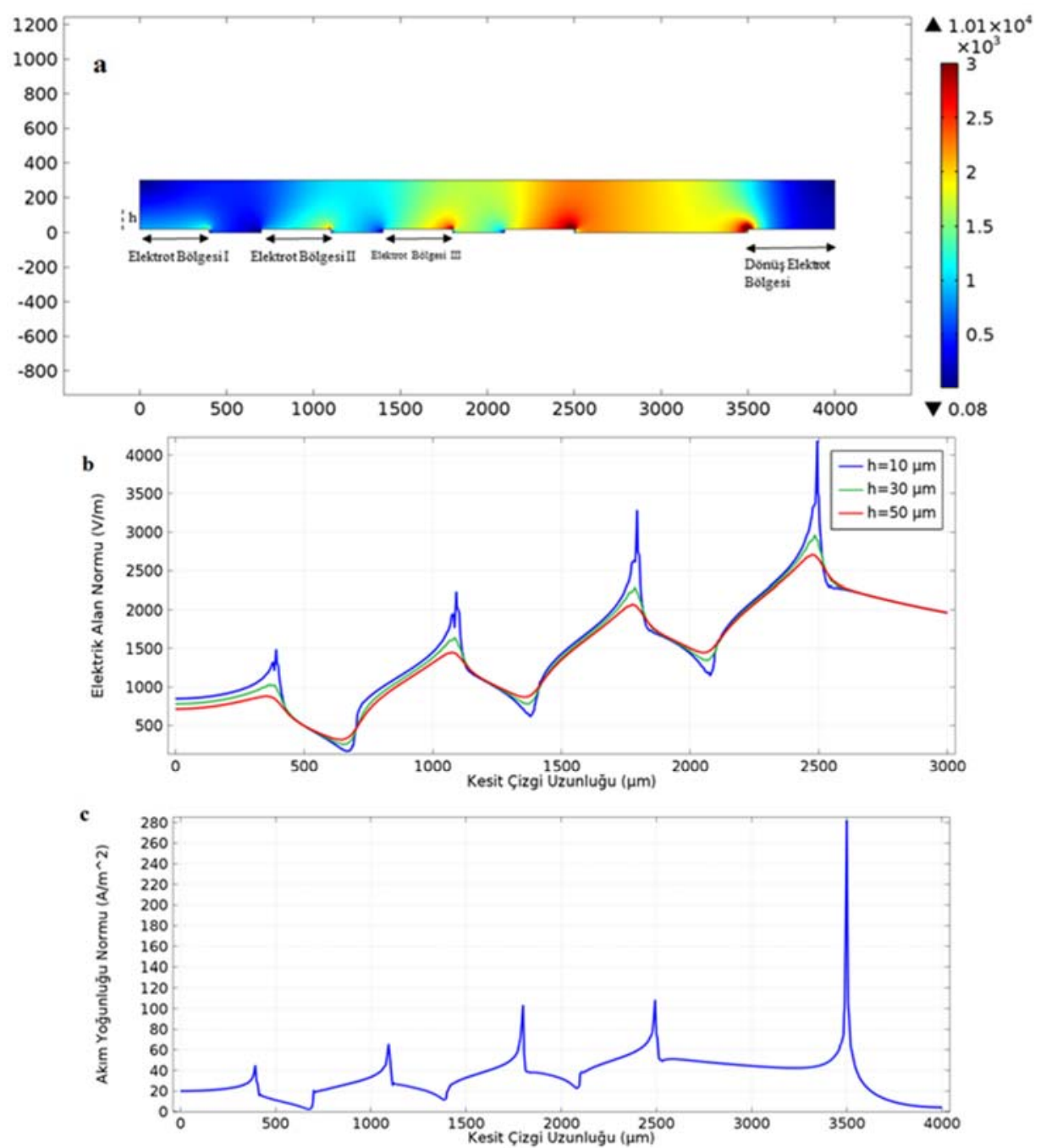

Şekil 3. Standart elektrot dizisinin $10 \mu \mathrm{A}$ genlikli bifazik uyartım vurusu ile uyartılması sonucu retina üzerindeki elektrik alan dağılımı ve akım yoğunluğu

(Electric field and current density distributions on retina as a result of $10 \mu \mathrm{A}$-biphasic electrical stimulation using standart electrode array) 

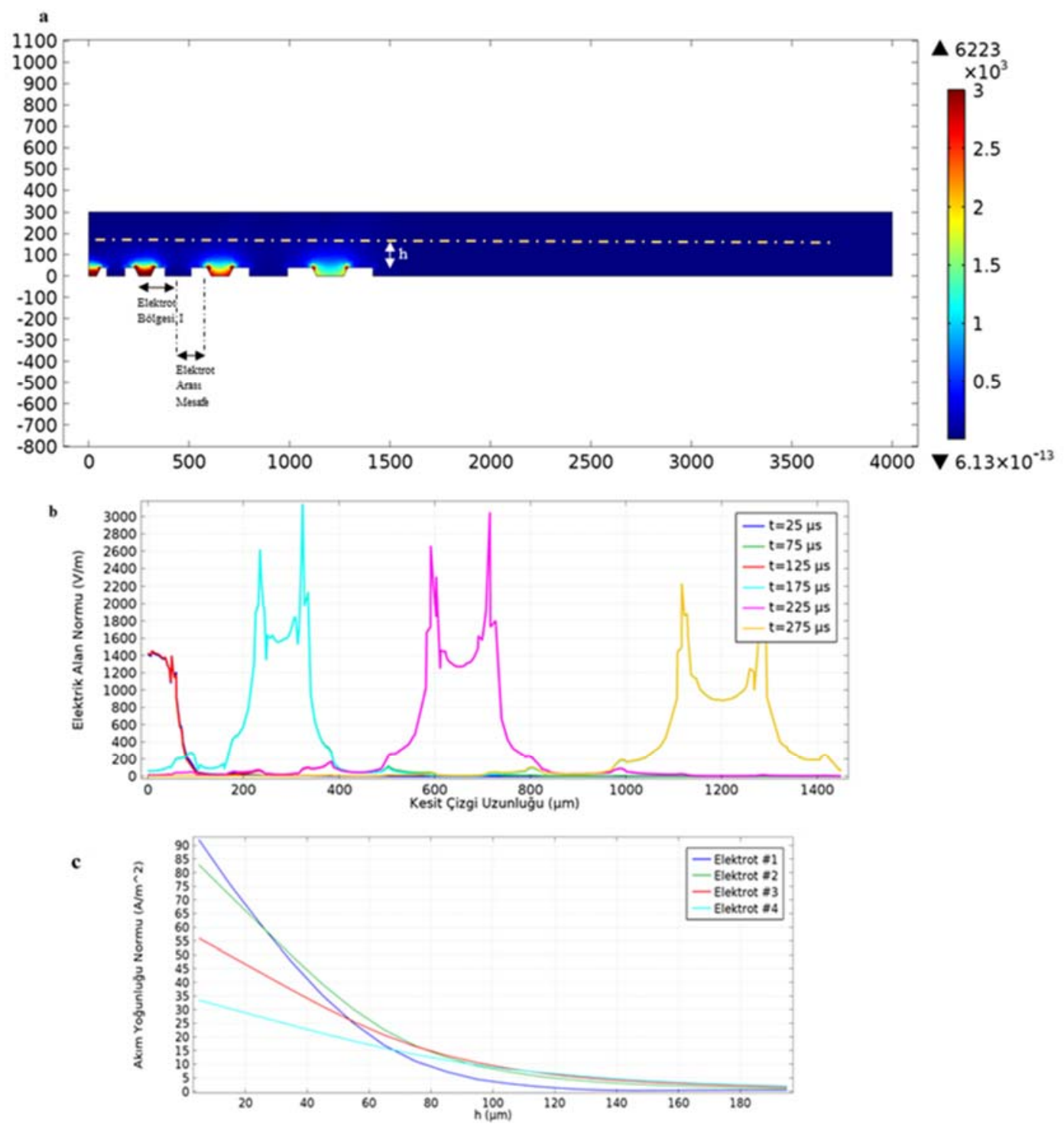

Şekil 4. Sunulan elektrot geometrisi ve uyartım stratejisi kullanılarak doku üzerinde ortaya çıkan dağılımlar (Field distributions using proposed electrode geometry and stimulation strategy)

Tablo 2. İşlemsel modellerin harcanan güç, yük yoğunluğu ve sıcaklık açısından karşılaştırılması (Comparison of computational models in terms of power dissipated, charge density and temperature)

\begin{tabular}{lccc}
\hline & Harcanan Güç $\left(\mathrm{mW} / \mathrm{mm}^{3}\right)$ & Yük Yoğunluğu $\left(\mathrm{nC} / \mathrm{m}^{3}\right)$ & Sicaklık Artış $\left({ }^{\circ} \mathrm{C}\right)$ \\
\hline Standart Model & 4,19 & 626,15 & 1,38 \\
Sunulan Model & 0,237 & 945,53 & 0,4 \\
\hline
\end{tabular}

olarak farklı olan uyartım sinyalleri $200 \mu$ s periyota sahiptir. Retina gangliyon hücrelerinin uyartılabilmesi için gereken elektrik alan dağılımını sağlayan uyartım akım genliği 0,5-2 $\mu \mathrm{A}$ kullanılarak elde edilmiştir (Şekil 4). Yarı koni biçimli elektrot geometrisi ve farklı elektrot aralıklarına sahip elektrot dizisinin uyartımında kullanılan uyartım yöntemi ile 0,5-2 $\mu \mathrm{A}$ ile hedeflenen elektrik alan aralığ 1 elde edilmiştir. Zaman kaymalı ağırlıklandırılmış uyartım sinyali sayesinde her bir elekrot sadece bir alternans aktiftir (Şekil 4-b). Akım yoğunluğu normu $100 \mathrm{~A} / \mathrm{m}^{2}$ 'den aşağıdadır. Sunulan modelde kullanılan yarı-koni biçimindeki elektrotun üst yüzeyindeki toprak elektrotu sayesinde elektrik alan sadece hedef bölgede oluşur. Oluşturulan bu lokalize uyartım sayesinde sinir hücresi boyutunda uyartım sağlanabileceğinden nöronların büyük kümeler halinde uyartımı dolayısıyla ortaya çıkan fosfen bozulumu ve sadece bir genel toprak elektrotu yerine bunu birleştirerek kullanmak sayesinde elektrot etkileşimi problemlerinin önüne geçilmiş olur. Akım yoğunluğu dağılımında da standart modelin aksine tehlikeli aralığa yükselerek elektrot korozyonuna neden olmaz. Bunun nedeni hem düşük genlikli uyartım sinyallerinin yeterli olması hem de her 
elektrotun toprağa benzer uzaklıklarda olmasıdır. Aynı anda tüm elektrotların ateşlenmesi yerine belirli elektrot gruplarının ateşlenmesi ortaya çıkabilecek elektrot etkileşimini en aza indirmiş, her bir elektrot etrafinda izole lokal uyartım bölgeleri oluşturmuştur. Şekil 4-b'de her elektrot sıralı olarak ateşlendiğinden oluşan elektrik alan arasında da bir zaman farkı vardır.

\subsection{Uyartım Sonucu Oluşan Sicaklık Etkisinin Incelenmesi (Investigation of Temperature Effect As a Result of Stimulation)}

Göz içi bölgeye yerleştirilerek uzun dönem vücutta kalması planlanan cihazların neden olacağı sıcaklık yan etkilerini tasarım aşamasında modelleme çalışmalarıyla incelemek kritik önem taşımaktadır. Sıcaklığa duyarlı olan retina dokusundaki sinir hücrelerinde meydana gelebilecek yüksek sıcaklık değişimleri sıcaklığa bağlı olan, gerilim kontrollü kanallar gibi, hücre zarı özelliklerini ve sinirsel ağ1 etkileyerek hücre ölümlerine neden olabilir [39, 40]. Normal vücut sıcaklığından 3 derece yüksek sıcaklık artışlarının çeşitli fizyolojik anormalliklere neden olacağı rapor edilmiştir [40, 41]. Ayrıca, guinea domuzu ve fare üzerinde yapılan çalışmalarda 2 ve 3 derecelik artışlardan sonra birtakım bozuklukların oluştuğu görülmüştür [42, 45]. Her iki elektrot dizisinin daha önceden belirtilen uyartım sinyalleri ile uyartımında yük yoğunlukları ile harcanan güç değerleri incelenmiştir (Tablo 2). Standart modelde harcanan güç 4,19 $\mathrm{mW} / \mathrm{mm}^{3}$ iken sunulan yöntemde 0,237 $\mathrm{mW} / \mathrm{mm}^{3}$ 'tür. Aynı anda tüm elektrotlar aktif olmadığından hem elektrot etkileşiminin önüne geçilmiş hem de güç tüketimi azaltılmıştır. Harcanan güce bağlı olarak doku üzerinde ortaya çıkan sıcaklık artışı belirlenmiştir. Şekil 5'de sıcaklık dağılımının etkisi sunulmuştur. Şekil 5-a,b standart modelin sıcaklık dağılımı ile dokudaki sıcaklık artışını gösterirken c-d sunulan modele dair dağılım ile farklı $\mathrm{h}$ değerleri için sıcaklık artışını göstermektedir. Standart modelde gözlemlenen sicaklık artış $1,38^{\circ} \mathrm{C}$ iken sunulan modelde artış $0,4^{\circ} \mathrm{C}$ 'dir. Şekil 5-b'de elektrot yüzeyindeki sıcaklık artışı ile dokunun derinliklerinde $\mathrm{h}=250 \mu \mathrm{m}$ için sıcaklık artışı sunulmuştur. Elektrot yüzeyinden uzaklaşıldıkça daha homojen bir sıcaklık artış1 gözlemlenmiştir. Diğer yandan, sunulan modelin elektrot yüzeyi yakınında, $\mathrm{h}=-30 \mu \mathrm{m}$, en yüksek sıcaklık artış1 oluşmuş toprak elektrotunun üzerinden alınan, $\mathrm{h}=10 \mu \mathrm{m}$ için, sıcaklık değerlerinde ise uyartım bölgesinin hizasında sicaklığın daha yüksek olduğu görülmüştür, Şekil 5-d. Göz içi bölgesine yerleştirilerek kronik olarak kullanılacak görsel protezler için harcanan güç ve sıcaklıktaki bu düşüş kritik önem taşımaktadır.

\subsection{Tavşan Retinası ile Gerçekleştirilen In Vitro Deneyler (In Vitro Experiments Using Rabbit Retina)}

Farklı genlik ve pals genişliğine sahip her bir uyartım vurusu ard arda $20 \mathrm{kez} 30 \mu \mathrm{m}$ çapında bir elektrot vasitasıyla uygulanmıştır. Her bir genlik için ardışık iki uyartım arasında gözlemlenen aksiyon potansiyeli sayısı rastgele oluşan aksiyon potansiyeli sayısından daha fazla ise o uyartımın aksiyon potansiyeli oluşturduğu kabul edilerek uygulanan genlik için başarı oranı tanımlanmış ve eşik belirlenmesinde kullanılmıştır. Elektriksel aktivitenin analizi ve aksiyon potansiyeli izolasyonunda Şekil 2'de verilen algoritma takip edilmiştir. Buna göre kaydedilen sinyal parçasının bir bölümü ile buradan izole edilerek üst üste bindirilmiş aksiyon potansiyelleri Şekil 6'da sunulmuştur. 9 elektrottan sağlıklı kayıtlar alınarak analiz aşamasında etkinlik oranı tanımı yapılmıştır. Etkinlik oranı elde edilen aksiyon potansiyellerinin pozitif sonuç veren elektriksel
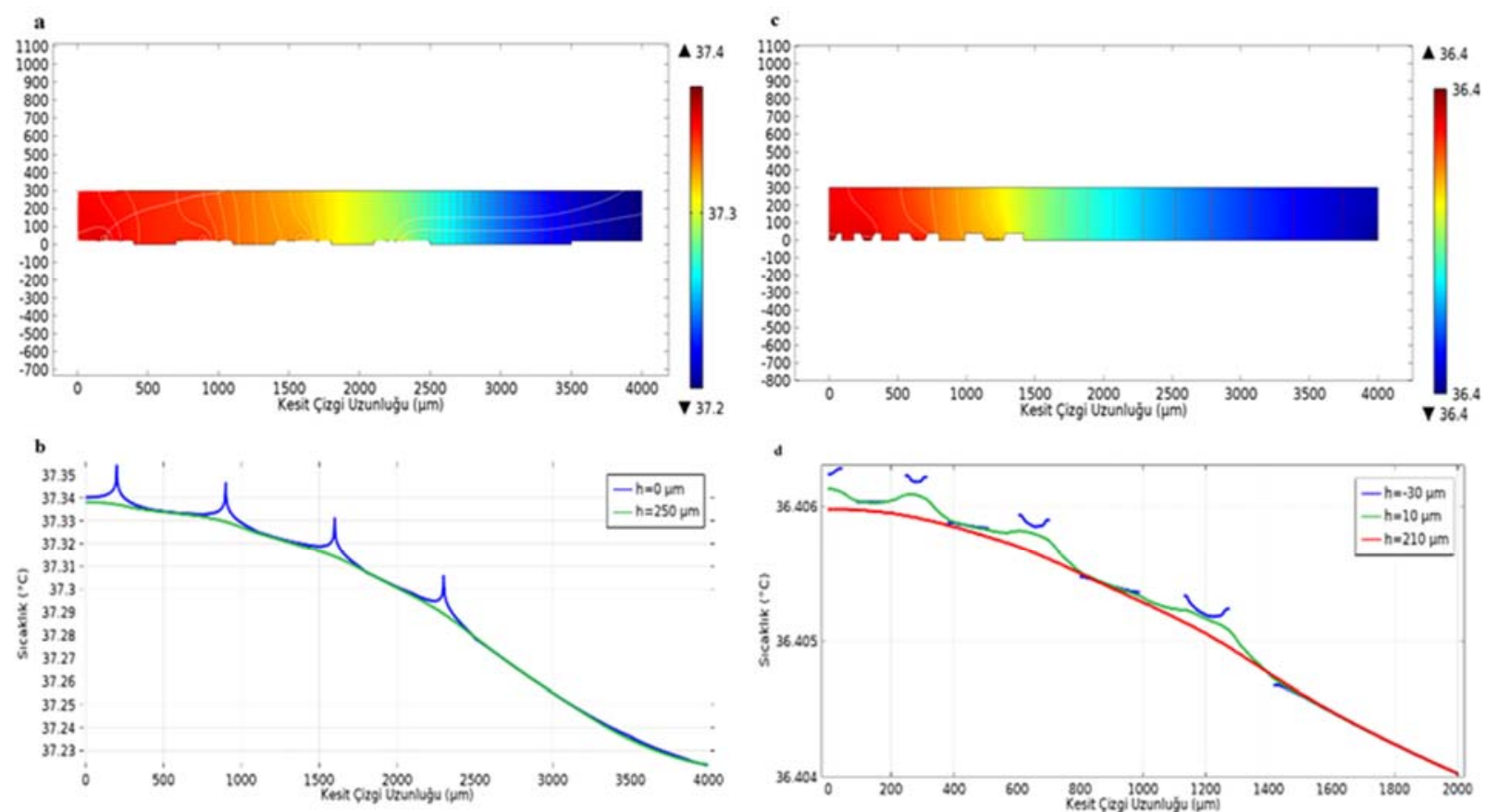

Şekil 5. Retina dokusu üzerinde uyartıma bağlı ortaya çıkan sıcaklık artışı (Temperature rise over the retina tissue depending on the stimulation) 

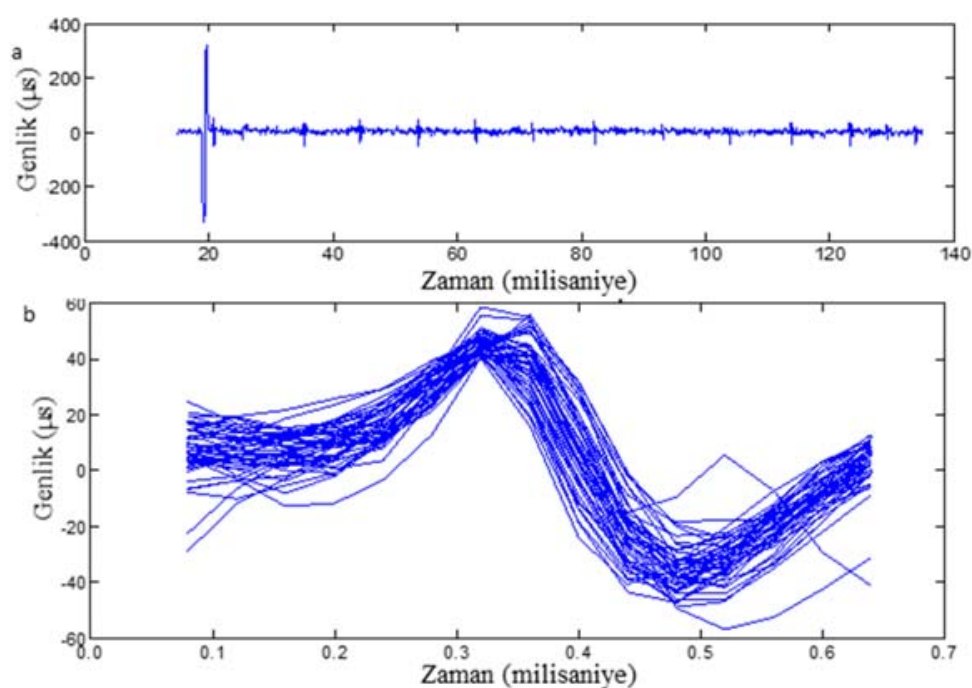

Şekil 6. Elektriksel aktivitenin analizinde aksiyon potansiyeli izolasyonu a) uyartım vurusunun ardından oluşan aksiyon potansiyelleri b) izole edilen aksiyon potansiyellerinin üst üste bindiriliși

(Spike isolation for analysis of electrical activity a) spikes that form after stimulation pulse b) overlaid spikes that isolated)

Tablo 3. In vitro deneylerde uyartım dalga formuna bağlı olarak elde edilen eşik akımı ve elektrotlarda görülen etkinlik (Activity ratios and threshold currents that are provided depending on the stimulation waveform during in vitro experiments)

\begin{tabular}{llllllll}
\hline Uyartım Tipi & \multicolumn{3}{l}{ Bifazik Uyartım } & \multicolumn{3}{c}{ Monofazik Uyartım } \\
\hline Çap $(\mu \mathrm{m})$ & 20 & 20 & 20 & 30 & 10 & 20 & 30 \\
Etkinlik Oranı (\%) & 23 & 30 & 28 & 20 & 15 & 49 & 23 \\
Uyartım Eşik Akımı $(\mu \mathrm{A})$ & $10 \mu \mathrm{A}$ & & \multicolumn{3}{l}{$50 \mu \mathrm{A}$} \\
\hline
\end{tabular}

uyartım sayısına oranıyla hesaplanmıștır. Sonuçlar Tablo 3 'te sunulmuştur. Bifazik uyartım için 4 uyartım kanalından alınan veriler kullanılmış olup bunların üçü $20 \mu \mathrm{m}$ biri 30 $\mu \mathrm{m}$ çapındadır. $20 \mu \mathrm{m}$ çaplı elektrotarın ortalama aktivasyon oranı \%27 iken $30 \mu \mathrm{m}$ çaplı elektrotun aktivasyon oranı $\% 20$ 'dir. Monofazik uyartım için 10, 20 ve $30 \mu \mathrm{m}$ çaplı elektrotların etkinlik oranları hesaplanmıştır. $10 \mu \mathrm{m}$ çaplı elektrotun etkinlik oranı $\% 15,20 \mu \mathrm{m}$ çaplı elektrot için \%49 ve $30 \mu \mathrm{m}$ çaplı elektrotların ortalaması \%23 olarak görülmüştür. Diğer yandan, bifazik ve monofazik uyartım sinyallerinin aksiyon potansiyeli oluşturmadaki etkinliği incelendiğinde bifazik uyartım sinyalleri ile uyartım akım genliği $10 \mu \mathrm{A}$ iken monofazik uyartım için bu $50 \mu \mathrm{A}$ olarak tespit edilmiştir. Burada, retina gangliyon hücre uyartımında bifazik dalga formlarının daha uygun ve özellikle küçük elektrot yapısının aksiyon potansiyeli algılamada etkili olduğu belirlenmiştir.

\section{SONUÇLAR (CONCLUSIONS)}

Görsel algının restorasyonunda en önemli amaç çeşitli biyolojik ve fiziksel kısıtlamalar altında kronik uyartım için güvenli sınırlarda uyartım ortamının sağlanması ve mümkün olan en yüksek çözünürlüğe ulaşmaktır. Hücre dışı nöral elektriksel uyartım mekanizmasının modellenmesi ve daha iyi anlaşılması için gerçekleştirilen çalışmalar, doku hasarını en aza indirerek hedef nöral yapıların uyartım başarısını en yüksek oranda sağlayacak nöral protezlerin geliştirilmesi hedefiyle devam etmektedir. Ayrıca, uyartım nedenli hücre dışı alanların nöral hücreler üzerindeki etkisinin daha iyi anlaşılmasını ve nöral protezlerin geliştirilmesinde güvenli uyartım sınırlarında uzaysal çözünürüğün artırılmasına dönük optimal yaklaşımların elde edilmesini sağlar. $\mathrm{Bu}$ çalışmada sunulan Merkez-Ağırlıklı Zaman Kaymalı Uyartım Stratejisi dahilindeki elektrot tasarımı, konfigürasyonu ve uyartım yöntemi ile gerek lokalize uyartım ile her bir elektrotun bağımsız bir piksel olarak çalışabilmesi gerekse de elektrot etkileşimi ortadan kaldırılarak lokalize uyartım ile daha düşük genliklerle çözünürlüğün artırılabilmesinin mümkün olduğu ortaya konulmuştur. Ayrıca, daha düşük güç tüketimi ve buna bağlı olarak dokuda ortaya çıkan sıcaklık artışı uygulanan uyartım yöntemiyle önemli ölçüde azaltılmıştır. In vitro deneyler ile retina gangliyon hücre uyartımında bifazik sinyallerin daha uygun ve küçük çaplı elektrotların aksiyon potansiyeli algılamada etkin olduğu görülmüștür. Önerilen yöntem görsel protez sistemlerinin çözünürlügünün artırılmasında ve düşük güç gereksinimi ve sicaklık etkisi nedeniyle kronik olarak kullanılacak cihazlarda performansı artıracağ sonucuna varılmıștır.

\section{TEŞEKKÜR (ACKNOWLEDGEMENT)}

$\mathrm{Bu}$ çalışma Türkiye Bilimsel ve Teknolojik Araştırma Kurumu (TÜBITAK) 113E181 nolu proje ile desteklenmiștir. 


\section{KAYNAKLAR (REFERENCES)}

1. Jonas J.B., George R., Asokan R., Flaxman S.R., Keeffe J., Leasher J., Prevalence and causes of vision loss in Central and South Asia: 1990-2010, Brit. J. Ophthalmol., bjophthalmol-2013, 2014.

2. Stronks H.C., Dagnelie G., The functional performance of the Argus II retinal prosthesis, Expert Rev. Med. Devices, 11 (1), 23-30, 2014.

3. Bourne R.R., Stevens G.A., White R.A., Smith J.L., Flaxman S.R., Price H., Causes of vision loss worldwide, 1990-2010: a systematic analysis, Lancet Glob Health, 1 (6), e339-e349, 2013.

4. Humayun M.S., Prince M., de Juan E Jr, Barron Y., Moskowitz M., Klock I.B., Milam A.H., Morphometric analysis of the extramacular retina from postmortem eyes with retinitis pigmentosa, Invest. Ophthalmol. Visual Sci., 40 (1), 143-8, 1999.

5. Sekirnjak C., Hottowy P., Sher A., Dabrowski W., Litke A.M., Chichilnisky E.J., Electrical stimulation of mammalian retinal ganglion cells with multielectrode arrays, J. Neurophysiol., 95 (6), 3311-3327, 2006.

6. Ferrari A.C., Bonaccorso F., Fal'Ko V., Novoselov K.S., Roche S., Bøggild P., Science and technology roadmap for graphene, related two-dimensional crystals, and hybrid systems, Nanoscale, 7 (11), 4598-4810, 2015.

7. Humayun M.S., Cruz L., Dagnelie G. ve ark., Argus II Study Group. Interim performance results from the second sight (R) ArgusTM II Retinal Prosthesis Study, The Association for Research in Vision and Ophthalmology 2010, Florida-Amerika Birleşik Devletleri, 2022, 2-6 Mayis, 2010.

8. Luo Y.H.L., da Cruz L., The Argus ${ }^{\circledR}$ II retinal prosthesis system, Prog. Retin. Eye Res., 89-107, 2016.

9. Edwards T.L., Cottriall C.L., Simunovic M.P., Ramsden J.D., Zrenner E., MacLaren R.E., Preliminary Findings from the Oxford Retinal Implant Alpha AMS Trial, Invest. Ophthalmol. Visual Sci., 57 (12), 2016.

10. Chow A.Y., Chow V.Y., Subretinal electrical stimulation of the rabbit retina, Neurosci. Lett., 225, 1316, 1997.

11. Allen PJ, Yeoh J, McCombe M, Heriot M, Heriot W, Luu C.D., Bionic Vision Australia - implantation of suprachoroidal retinal prosthesis- results for the first participants, Invest. Ophthalmol. Visual Sci., 54, 1031, 2013.

12. Krantz J.H., Experiencing Sensation and Perception, Pearson Education, Amerika Birleşik Devletleri, 2012.

13. Collins C.M., Smith M.B., Turner R., Model of local temperature changes in brain upon functional activation, J Appl Physiol, 97, 2051-2055, 2004.

14. Connor C.W., Hynynen K., Patterns of thermal deposition in the skull during transcranial focused ultrasound surgery, IEEE Trans. Biomed. Eng., 51 (10), 1693-1706, 2004.

15. Gosalia K., Weiland J., Humayun M., Lazzi G., Thermal elevation in the human eye and head due to the operation of a retinal prosthesis, IEEE Trans. Biomed. Eng., 51 (8), 1469-1477, 2004
16. Talukder M.I., Implantable Neural Stimulation and Neural Response Reading Microsystems Design for Wireless Retinal and Auditory Prostheses, PhD Thesis, Electrical Engineering, Graduate School of Wayne State University, A.B.D., 2007.

17. Rao S.S., The Finite Element Method in Engineering, Elsevier Science and Technology Books, Amerika Birleşik Devletleri, 2010.

18. Alonso Orozco F., Finite Element Method Modelling and Simulations for Comparison between Deep Brain Stimulation Electrodes, Master Thesis, Linköping University, The Institute of Technology, 2012.

19. Malmivuo J., Plonsey R., Bioelectromagnetism, Oxford University Press, New York, 1995.

20. Tandon N., Electrical stimulation for cardiac tissue engineering, $\mathrm{PhD}$ Thesis, Biomedical Engineering, Columbia University, 2009.

21. Durand D., Bronzino J.D., Electric Stimulation of Excitable Tissue, The Biomedical Engineering Handbook, 229-251, 1995.

22. Cannizzaro C., Tandon N., Figallo E., Practical aspects of cardiac tissue engineering with electrical stimulation, Methods Mol. Med., 140, 291-307, 2007.

23. Kim S., Tathireddy P., Normann R.A., Solzbacher F., Thermal impact of an active 3-D microelectrode array implanted in the brain, IEEE Trans. Neural Syst. Rehabil. Eng., 15 (4), 493-501, 2007.

24. Chang I., Finite element analysis of hepatic radiofrequency ablation probes using temperaturedependent electrical conductivity, Biomed. Eng. Online, 2-12, 2003.

25. Greenwald S.H., Horsager A., Humayun M.S., Greenberg R.J., McMahon M.J., Fine I., Brightness as a function of current amplitude in human retinal electrical stimulation, Invest. Ophthalmol. Visual Sci., 50 (11), 5017-25, 2009.

26. Yanai D., Weiland J.D., Mahadevappa M., Greenberg R.J., Fine I., Humayun M.S., Visual performance using a retinal prosthesis in three subjects with retinitis pigmentosa, Am. J. Ophthalmol., 43 (5), 820-827, 2007.

27. Fujikado T., Kamei M., Sakaguchi H., Kanda H., Morimoto T., Ikuno Y., Testing of semichronically implanted retinal prosthesis by suprachoroidaltransretinal stimulation in patients with retinitis pigmentosa, Invest. Ophthalmol. Visual Sci., 52 (7), 4726-33, 2011.

28. Ahuja A.K., Behrend M.R., Kuroda M., Humayun M.S., Weiland J.D., An in vitro model of a retinal prosthesis, IEEE Trans. Biomed. Eng., 55 (6), 1744-53, 2008.

29. Joucla S., Yvert B., Modeling of extracellular neural stimulation: from basic understanding to MEA-based applications, J Physiol Paris, 106, 146-58, 2012.

30. Abramian M., Lovell N.H., Morley J.W., Suaning G.J., Dokos S., Activation of retinal ganglion cells following epiretinal electrical stimulation with hexagonally arranged bipolar electrodes, J. Neural Eng., 8 (3), 2011.

31. Ghazavi A., Westwick D., Xu F., Wijdenes P., Syed N., Dalton C., Effect of planar microelectrode geometry on neuron, stimulation: finite element modeling and 
experimental validation of the electrode shape, $\mathrm{J}$. Neurosci. Methods, 248, 51-8, 2015.

32. Mueller J.K., Grill W.M., Model-based analysis of multiple electrode array stimulation for epiretinal visual prostheses, J. Neural Eng., 10 (3), 036002, 2013.

33. Schiefer M.A., Grill W.M., Sites of neuronal excitation by epiretinal electrical stimulation, IEEE Trans Neural Syst Rehabil Eng., 14 (1), 5-13, 2006.

34. Kasi H., Bertsch A., Guyomard J.L., Kolomiets B., Picaud S., Pelizzone M., Renaud P., Simulations to study spatial extent of stimulation and effect of electrode-tissue gap in subretinal implants, Med. Eng. Phys., 33 (6), 755-763, 2011.

35. Kasi H., Hasenkamp W., Cosendai G., Bertsch A., Renaud P., Simulation of epiretinal prosthesesEvaluation of geometrical factors affecting stimulation thresholds, J. NeuroEng. Rehabil., 8 (1), 2011.

36. Wilke R.G.H., Moghadam G.K. Lovell, N.H., Suaning G.J., Dokos S., Electric crosstalk impairs spatial resolution of multi-electrode arrays in retinal, J. Neural Eng., 8 (4), 046016, 2011.

37. Moghaddam G.K., Lovell N.H., Wilke R.G., Suaning G.J., Dokos S., Performance optimization of current focusing and virtual electrode strategies in retinal implants, Comput. Methods Programs Biomed., 117 (2), 334-342, 2014.

38. Palanker D., Vankov A., Huie P., Baccus S. Design of a high-resolution optoelectronic retinal prosthesis, J. Neural Eng., 2 (1), 105, 2005.
39. Elwassif M.M., Kong Q., Vazquez M., Bikson M., Bioheat transfer model of deep brain stimulation-induced temperature changes, J. Neural Eng., 3, 306-315, 2006.

40. Seese T.M., Harasaki H., Saidel G.M., Davies C.R., Characterization of tissue morphology, angiogenesis, and temperature in the adaptive response of muscle tissue in chronic heating, Lab Invest., 78, 1553-1562, 1998.

41. Celik M.E., Karagoz I., Modelling of Stimulation Environment Using Monophasic Rectangle Pulse for Various Stimulation Parameters, Acta Phys. Pol. A, 128, 2015.

42. Ueda M., Bures J., Fischer J., Spreading depression elicited by thermal effects of ultrasonic irradiation of cerebral cortex in rats, J. Neurobiol., 8, 381-393, 1977.

43. Fujii T., Ibata Y., Effects of heating on electrical activities of guinea pig olfactory cortical slices, Eur. J. Physiol., 392, 257-260, 1982.

44. Wang H., Wang B., Normoyle K.P., Jackson K., Spitler K., Sharrock M.F., Brain temperature and its fundamental properties: a review for clinical neuroscientists, Front. Neurosci., 8, No 307, 2014.

45. Gulcan O., Uslan I., Usta Y., Cogun C., Effect of use of cu-cr $\mathrm{p} / \mathrm{m}$ electrodes on machining performance of electric discharge machining, Journal of the Faculty of Engineering and Architecture of Gazi University, 30 (3), 381-394, 2015. 
